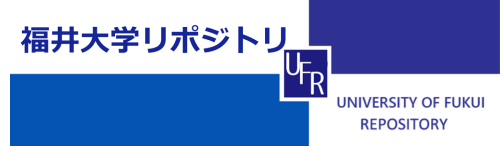

Cat al yt i c gener at i on of chl or i ne wi th sl i ght over pot ential by micel I ar ferrocene

\begin{tabular}{|l|l|}
\hline 著者 & AOK Koi chi , CHEN Han, CHEN Ji ngyuan \\
\hline $\begin{array}{l}\text { j our nal or } \\
\text { publ i cat i on t i t l e }\end{array}$ & El ect r ochemi st ry Communi cat i ons \\
\hline vol une & 9 \\
\hline number & 9 \\
\hline page r ange & 2304 2307 \\
\hline year & $2007-09$ \\
\hline URL & ht t p: //hdl . handl e. net /10098/1772 \\
\hline
\end{tabular}




\title{
Catalytic generation of chlorine with slight overpotential by
}

\author{
micellar ferrocene \\ Koichi Aoki ${ }^{*}$, Han Chen, Jingyuan Chen \\ Department of Applied Physics, University of Fukui, 3-9-1 Bunkyo, Fukui-shi, \\ 910-8507 Japan
}

\begin{abstract}
Ferrocene solubilized with poly(vinylpyrrolidone) in aqueous $\mathrm{KCl}$ solution exhibited a well-defined voltammetric peak at $1.33 \mathrm{~V}$ vs. $\mathrm{Ag} \mid \mathrm{AgCl}$ at a platinum electrode. The wave was attributed to the oxidation of chloride to chlorine, demonstrated by smell of chlorine, by a view of formation of gas bubbles, by coloration through the reaction with diethyl-p-phenylene diamine, and by the increase in the anodic current with the concentration of chloride. Since no wave was observed in the ferrocene-free solution or $\mathrm{KCl}$-free solution in this potential domain, the reaction mechanism was suggested to be the oxidation of chloride into chlorine catalyzed by micellar ferrocene. The potential at the foot of the wave $(1.08 \mathrm{~V})$ was less positive that the standard potential of $\mathrm{Cl}_{2} / \mathrm{Cl}^{-}$, and hence the reaction may be useful for enhancing the energetic efficiency at chlor-alkali industry. The value of the peak current was one-sixth the theoretical diffusion-controlled current, and was proportional to the square-root of the potential scan rate.
\end{abstract}

key words: chlorine, catalytic current, micellar ferrocene, surfactant, poly(vinylpyrrolidone)

\footnotetext{
* corresponding author, e-mail d930099@icpc00.icpc.fukui-u.ac.jp, fax +81 77627 8494
} 


\section{Introduction}

Electrochemical generation of chlorine has been industrially carried out at a ruthenium oxide-coated titanium electrode, called a dimensionally stable anode (DSA), and has played a central role in the chlor-alkali industry [1,2]. The DSA is much superior to carbon electrodes in low overpotential as well as a long life for the oxidation $[3,4]$. The low overpotential has resulted from the catalytic activity of ruthenium oxide [4,5]. The mechanistic work has been limited [6-8], because of complications by side reactions. The high activity leads to a loss of selectivity of oxidation of water so that the anodic voltammogram for chloride has not been well identified.

The catalytic activity for the oxidation of chlorine may be provided by conventional redox active catalysts such as ferrocenyl derivatives, metal porphyrins and viologens. However, study on the catalysis for chlorine has been restricted to photo-induced processes $[9,10]$, modification of electrode surface $[11,12]$ and exploitation of catalysts [13-16]. A homogeneous catalyst is favorable in order to avoid instability of catalyst by adsorption or desorption, which depends on the redox states owing to change in the charge. Homogeneity can be readily realized by dispersing a catalyst deliberately in solution by use of surfactants [17] or an amphiphilic catalyst [18]. We attempted here a combination of non-ionic surfactant, poly(vinylpyrrolidone), and ferrocene to examine the catalytic oxidation of chlorine. A non-ionic surfactant is preferable to ionic surfactants in that it can keep the solubility even at high concentration of chloride [19].

\section{Experimental}

Ferrocene (Kanto), potassium chloride (Nacalai Tesque), potassium nitrate (Wako), and poly(vinylpyrrolidone) (Wako) were of analytical grade. The agent (Kanto) by the 
diethyl-p-phenylenediamine method (DPD) was used as received. Water was distilled and deionized.

The voltammetric measurements were carried out at platinum disk electrode 1.6 mm in diameter with a potentiostat, Compactstat (Ivium Tech., Netherlands). Each voltammogram was taken after polishing the electrode surface with alumina powder. The surface of the electrode was monitored through a digital microscope. UV-vis spectrometer was V-570 (JASCO, Tokyo).

\section{Results and Discussion}

Figure 1 shows the cyclic voltammogram (a) of the $0.5 \mathrm{M} \mathrm{KCl}$ aqueous solution in which ferrocene was solubilized with PVP, where undissolved ferrocene was precipitated on the bottom of the cell. The anodic wave rose at $1.08 \mathrm{~V}$ vs. Ag|AgCl, exhibiting a peak at $1.36 \mathrm{~V}$, whereas the small cathodic wave appeared at $0.97 \mathrm{~V}$ for the backward scan. These waves were not observed when the solution did not contain ferrocene (Fig.1 (b)) or PVP (Fig.1 (c)). The wave (c) was identical with the wave of only $0.5 \mathrm{M} \mathrm{KCl}$ solution. Therefore these peaks are caused by ferrocene. A slightly larger current of (b) than that of (c) may be due to a trace amount of ferrocene (40 $\mu \mathrm{M})$ $[20,21]$. When the salt $(\mathrm{KCl})$ was replaced by $\mathrm{KNO}_{3}$, neither anodic or cathodic wave was observed. Consequently, the waves are not ascribed only to ferrocene but also to chloride. It is obvious that the value of the anodic peak is too large for the oxidation of micellar ferrocene.

In order to identify the product at the potential more positive than $1.08 \mathrm{~V}$, we applied $1.4 \mathrm{~V}$ for a half minute in the $0.5 \mathrm{M} \mathrm{KCl}+$ ferrocene $+4 \%$ PVP solution. Then we found formation of bubbles on the electrode surface and smelled chlorine. Chlorine was identified through the coloration to red by adding the DPD agent. The formation of 
chlorine with the aid of ferrocene suggests the catalytic reaction:

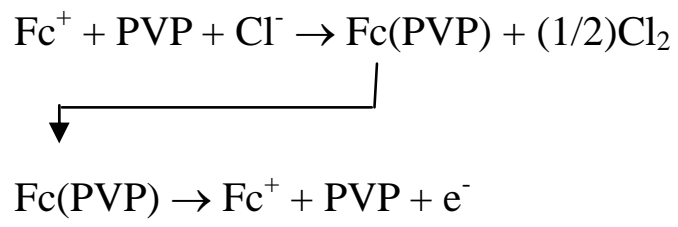

where ferrocene (Fc) must take a micellar form (Fc(PVP)) with the help of PVP. The standard potential of $\mathrm{Cl}_{2} / \mathrm{Cl}^{-}$is $1.14 \mathrm{~V}$ vs. $\mathrm{Ag} \mid \mathrm{AgCl}$, which is at the middle of the anodic $(1.36 \mathrm{~V})$ and the cathodic (0.97) peak potentials. The oxidation of chloride occurs almost thermodynamically. Although the standard potential of $\mathrm{O}_{2}+\mathrm{H}^{+} / \mathrm{H}_{2} \mathrm{O}$ is $1.02 \mathrm{vs}$. $\mathrm{Ag} \mid \mathrm{AgCl}$, decomposition of water does not contribute to the oxidation.

Multi-scan voltammograms caused a decrease in the anodic peak current with the number of the cycles. Small bubbles were observed on the electrode surface after three cycles of voltammetry. The bubbles may be responsible for the decrease in the current. Wiping the electrode surface recovered the value of the peak current.

We examined the variation of the anodic peak current with concentration of $\mathrm{Cl}^{-}$by adding $\mathrm{KCl}$ solution to $2.0 \mathrm{M} \mathrm{KNO}_{3}+$ ferrocene + $4 \%$ PVP solution, and showed it in Fig. 2. The addition increased the anodic peak current as well as the cathodic one, implying the indispensable responsibility of chloride for the anodic wave. Especially, the variation is close to the second order with respect to the concentration of $\mathrm{Cl}^{-}$. Therefore, reaction (1) stands for only a concept of the catalytic reaction but does not express the reaction mechanism.

The contribution of mass transfer of chloride was investigated by varying the potential scan rate, $v$. Figure 3 shows the variation of the anodic and the cathodic peak currents with $v^{1 / 2}$. The proportional relation for the anodic current suggests the diffusion-control of chloride rather than control by the catalytic reaction rate. Otherwise, the anodic current should be independent of $v$. The values of the anodic peak currents were only $16 \%$ of the theoretical value of the diffusion-controlled current. The current is controlled partially by diffusion of $\mathrm{KCl}$ owing to a supply by the depression of the 
concentration. In contrast, the cathodic peak current showed a proportional relation with $v$ rather than $v^{1 / 2}$ (see the lower $x$-axis), and hence is caused by adsorption. Chlorine, the product of reaction (1), is adsorbed on an electrode because of its hydrophobicity. The proportionality of the cathodic peak current to $v$ is a reasonable result for supporting reaction (1).

It is necessary to estimate the concentration of micellar ferrocene. We evaluated the concentration by means of UV vis-spectra and voltammetry. Figure 4 shows the spectra of the ferrocene $+\mathrm{KCl}$ solution. A band at $420 \mathrm{~nm}$ specific to Fc [22] was barely observed in the magnified curve (b') in the inset figure because of a low solubility (0.04 $\mathrm{mM}$ ) of ferrocene in water. The band $250 \mathrm{~nm}$ can be attributed to the $\pi-\pi^{*}$ transition of pentadienyl rings. When PVP was added to the solution, this absorbance was increased 8 times, implying the enhancement of the solubility. The band at $628 \mathrm{~nm}$, which can be assigned to ferricinium ion [23] generated by the oxidation by air, increased also 8 times with the addition of PVP. Thus the concentration of micellar ferrocene is estimated to be $0.3(=0.04 \times 8) \mathrm{mM}$.

The micellar ferrocene itself should show the oxidation current according to reaction (2). The anodic peak at $0.9-1.05 \mathrm{~V}$ is predicted to be due to $0.3 \mathrm{mM}$ micellar ferrocene. We tried to detect ferricinium ion in the reverse scan by changing the reverse potentials. Figure 5 shows voltammograms of (a) $\mathrm{KCl}+\mathrm{Fc}+\mathrm{PVP}$ and (b) $\mathrm{KNO}_{3}+\mathrm{Fc}+$ PVP at various values of the reverse potentials. The cathodic wave at $0.2 \mathrm{~V}$, which has been identified to be ferricinium ion [24,25], did not appear until the reverse potentials were more positive than $1.0 \mathrm{~V}$ for $\mathrm{KCl}$ and $0.8 \mathrm{~V}$ for $\mathrm{KNO}_{3}$. Therefore reaction (2) ought to occur to yield ferricinium ion at $1.0 \mathrm{~V}$ for $\mathrm{KCl}$ and $0.8 \mathrm{~V}$ for $\mathrm{KNO}_{3}$. The difference in the oxidation potentials for $\mathrm{KCl}$ and $\mathrm{KNO}_{3}$ may be ascribed to the difference in the affinity of the surfactant (PVP) to the anions. The electroinactivity of $\mathrm{Fc}(\mathrm{PVP})$ in the wide potential domain $(0.0-0.9 \mathrm{~V})$ is contrast to the electroactivity of ferrocene micellized with sodium dodecylsulphate [21,26], which exhibited the anodic 
peak at potential close to that of dissolved ferrocene $(0.2 \mathrm{~V})$. The overpotential of 0.7 (= 0.9 - 0.2) V for Fc(PVP) implies that PVP may enclose sufficiently a ferrocene molecule in aqueous solution so that it prevents the active site of ferrocene from coming in contact with the electrode. The hard core formation has been suggested from the dependence of diffusion coefficients on concentration of salt [27].

The values of the anodic wave of $\mathrm{Fc}(\mathrm{PVP})$ at $1.0 \mathrm{~V}$ were proportional to $v^{1 / 2}$, as is shown in Fig. 6. Therefore the current should be controlled by diffusion of Fc(PVP). From the slope of the line in Fig. 6, we estimated the concentration of Fc(PVP) to be 0.2 $\mathrm{mM}$ on the assumption of the same value of the diffusion coefficient as of Fc. This concentration is smaller than the value $(0.3 \mathrm{mM})$ evaluated from the UV spectra. The underestimation by the voltammogram is ascribed to the smaller diffusion coefficient of micellar ferrocene than that of ferrocene.

A question arises about the reason why the electrocatalysis of chloride by $\mathrm{Fc}^{+}(\mathrm{PVP})$ occurred at the potential $(1.15-1.35 \mathrm{~V})$ more positive than the oxidation potential $(1.05 \mathrm{~V})$ of $\mathrm{Fc}(\mathrm{PVP})$. The potential of the catalytic current should be close to or more negative than the oxidation of the mediator [28]. In order to resolve the discrepancy, at least one more step at ca. $1.2 \mathrm{~V}$ should be taken into account, for example,

$\mathrm{Fc}^{+}(\mathrm{PVP})+\mathrm{Cl}^{-} \rightarrow \mathrm{Fc}(\mathrm{PVP}) \mathrm{Cl}$

$\mathrm{Fc}(\mathrm{PVP}) \mathrm{Cl}+\mathrm{Cl}^{-} \rightarrow \mathrm{Fc}(\mathrm{PVP})+\mathrm{Cl}_{2}+\mathrm{e}^{-}$

Combining reactions (3) and (4) with the reaction equivalent to (2)

$\mathrm{FC}^{+}(\mathrm{PVP})+\mathrm{e}^{-} \rightarrow \mathrm{FC}+\mathrm{PVP}$

we obtain

$\mathrm{Fc}+\mathrm{PVP}+2 \mathrm{Cl}^{-} \rightarrow \mathrm{Fc}(\mathrm{PVP})+\mathrm{Cl}_{2}+2 \mathrm{e}^{-}$

The rate of this reaction or the current is expressed by

$I=k[\mathrm{Fc}][\mathrm{PVP}]\left[\mathrm{Cl}^{-}\right]^{2}$

This suggests a quadratic relation of the current with $\left[\mathrm{Cl}^{-}\right]$, as is in accord with the 
variation in Fig. 2. Reaction (5) is essentially the same as reaction (1) except for the stoichiometric number, and hence the catalysis proceeds in principle via reaction (2).

\section{Conclusion}

Chlorine was generated at the potential close to the standard potential of $\mathrm{Cl}_{2} / \mathrm{Cl}^{-}$ when ferrocene was used for a catalyst of which solubility was enhanced with PVP. The reaction can be suggested to be catalytic, given by the combination of reactions (1), (2) or that of reactions (2'), (3), (4), although the detailed mechanism has not been obtained yet. The anodic wave was well-defined, as if it were an idealized diffusion-controlled voltammogram. The reaction discriminates against the formation of oxygen, and hence may be applied to selective generation of chlorine in chlor-alkali industry. The anodic peak current was partially diffusion-controlled but caused by the catalytic reaction. The cathodic current was controlled by the adsorption of chlorine.

\section{Figure Captions}

Fig. 1 Voltammograms of (a) $0.5 \mathrm{M} \mathrm{KCl}$ aqueous solution including ferrocene with the help of $4 \%$ PVP and (b, dashed curve) $0.5 \mathrm{M} \mathrm{KCl}$ including a trace amount of ferrocene without PVP, (c) $0.5 \mathrm{M} \mathrm{KCl}$ including $4 \% \mathrm{PVP}$ at $v=0.05 \mathrm{~V} \mathrm{~s}^{-1}$ on the Pt electrode. The inset is the magnification of the current domain from -30 to $20 \mu \mathrm{A}$.

Fig. 2 Variation of the anodic (circles) and the cathodic (triangles) peak currents with concentration of chloride at the scan rate of $0.07 \mathrm{~V} \mathrm{~s}^{-1}$ when $3.5 \mathrm{M} \mathrm{KCl}$ was added to the solution of $2.0 \mathrm{KNO}_{3}+$ ferrocene $+4 \%$ PVP.

Fig. 3 Variations of the anodic (circles) and the cathodic (triangles) peak currents with the square-root of the potential scan along the upper $x$-axis, and of the cathodic (filled 
triangles) peak currents with the potential scan along the lower $x$-axis in the solution of $0.5 \mathrm{M} \mathrm{KCl}+$ ferrocene $+4 \% \mathrm{PVP}$.

Fig. 4 UV-vis spectra of (a) Fc $+4 \% \mathrm{PVP}+0.5 \mathrm{M} \mathrm{KCl}$ and (b) Fc $+0.5 \mathrm{M} \mathrm{KCl}$.

Fig. 5 Voltammograms of (a) $0.5 \mathrm{MKCl}+\mathrm{Fc}+4 \% \mathrm{PVP}$ and (b) $0.05 \mathrm{M} \mathrm{KNO}_{3}+\mathrm{Fc}+$ $4 \%$ PVP at various values of the reverse potentials for $v=0.05 \mathrm{~V} \mathrm{~s}^{-1}$.

Fig.6 Dependence of the anodic current at $1.0 \mathrm{~V}$ in the solution of $0.5 \mathrm{M} \mathrm{KCl}+$ ferrocene $+4 \%$ PVP on the square-root of the scan rate. 


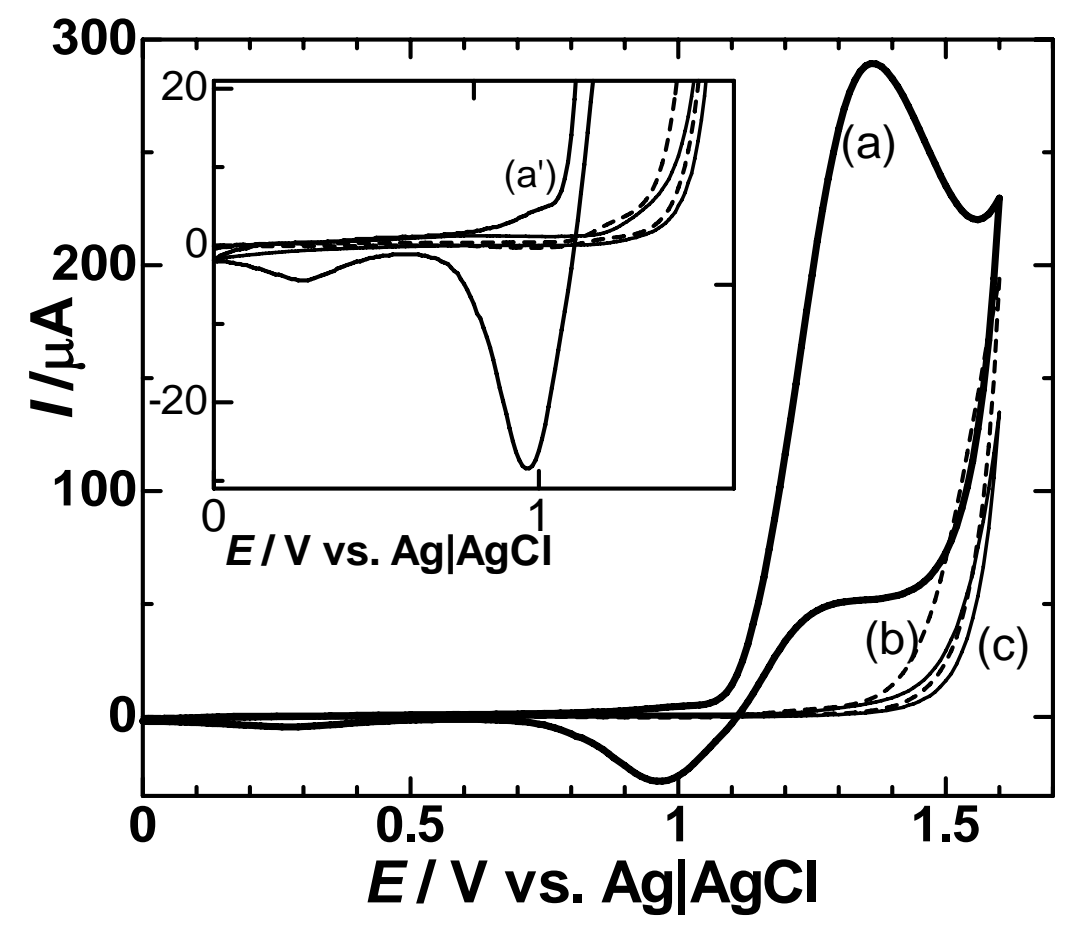

Fig. 1

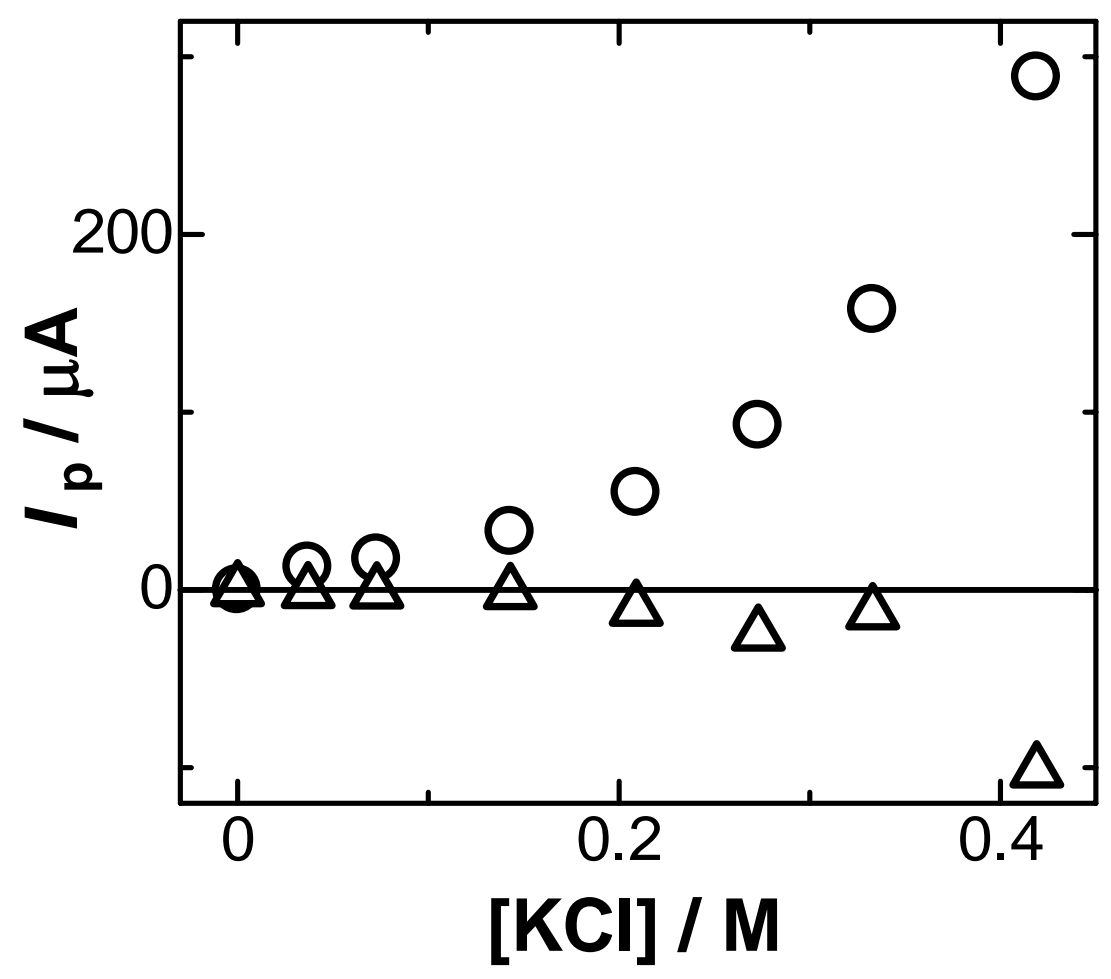

Fig. 2 


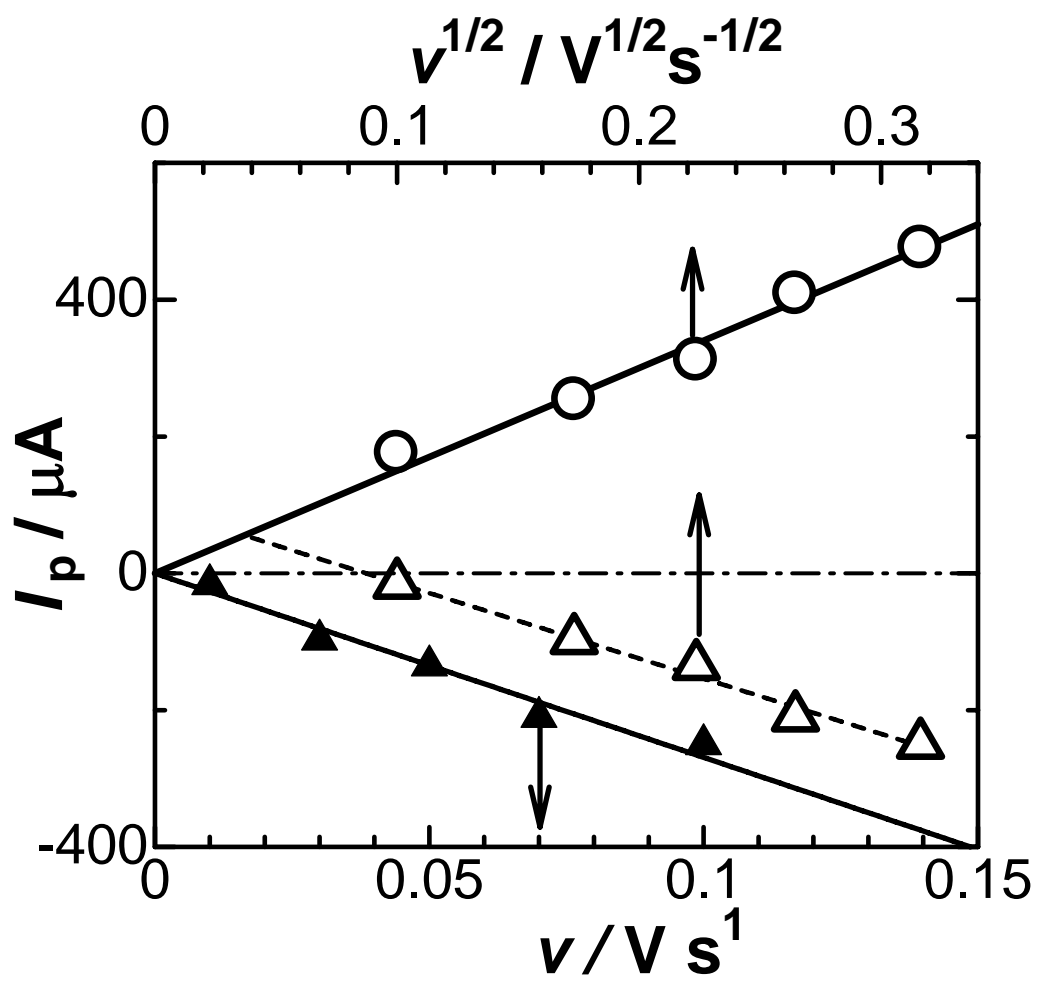

Fig. 3

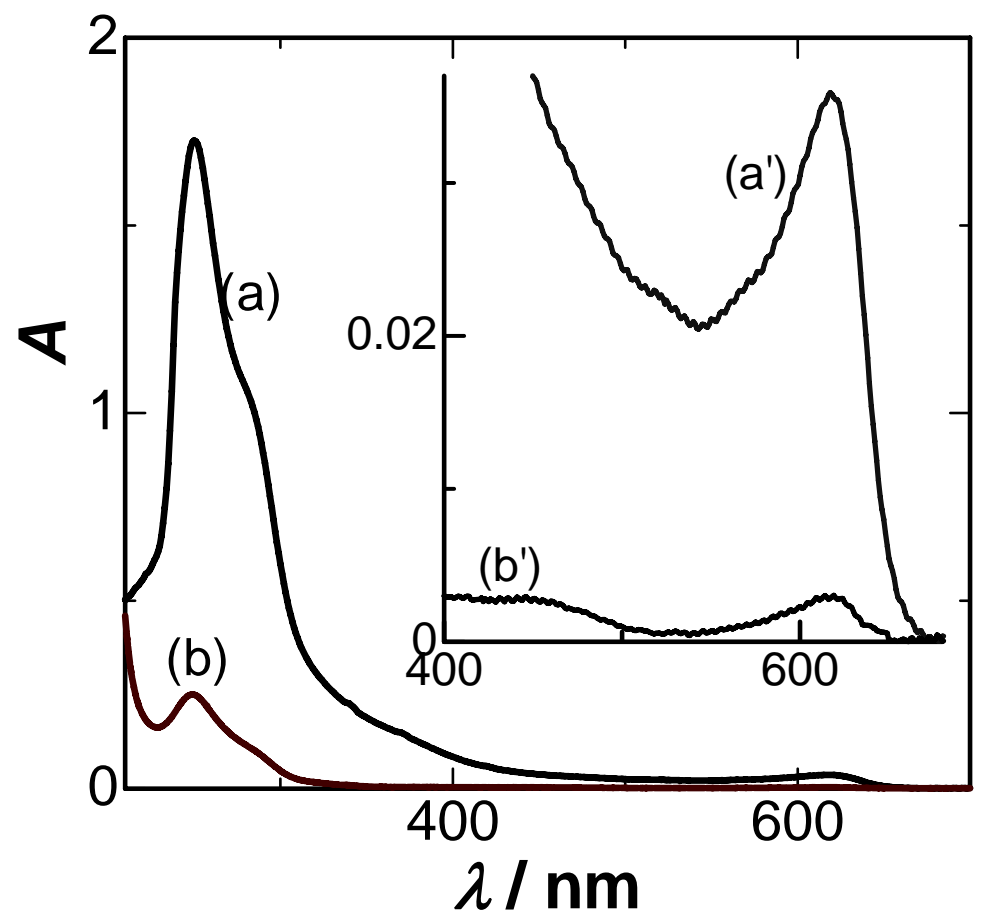

Fig. 4 


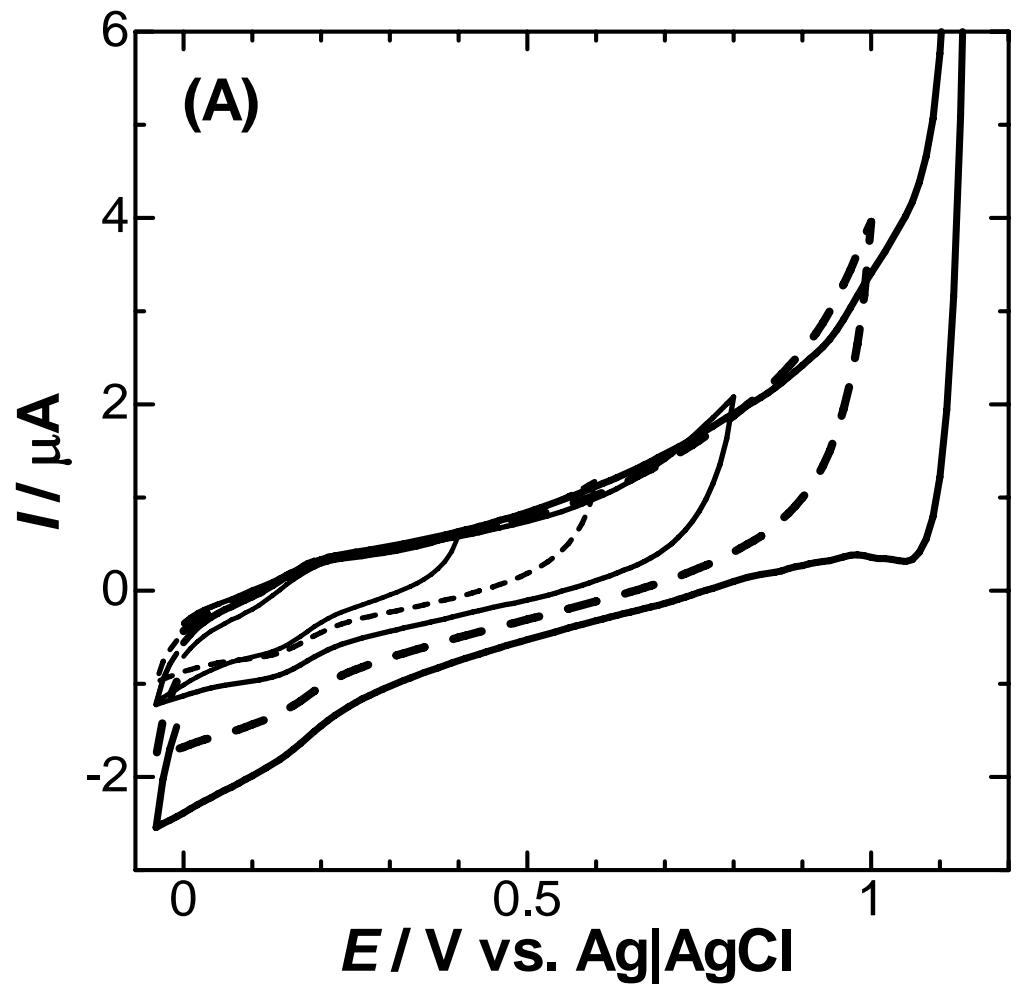

Fig. 5A

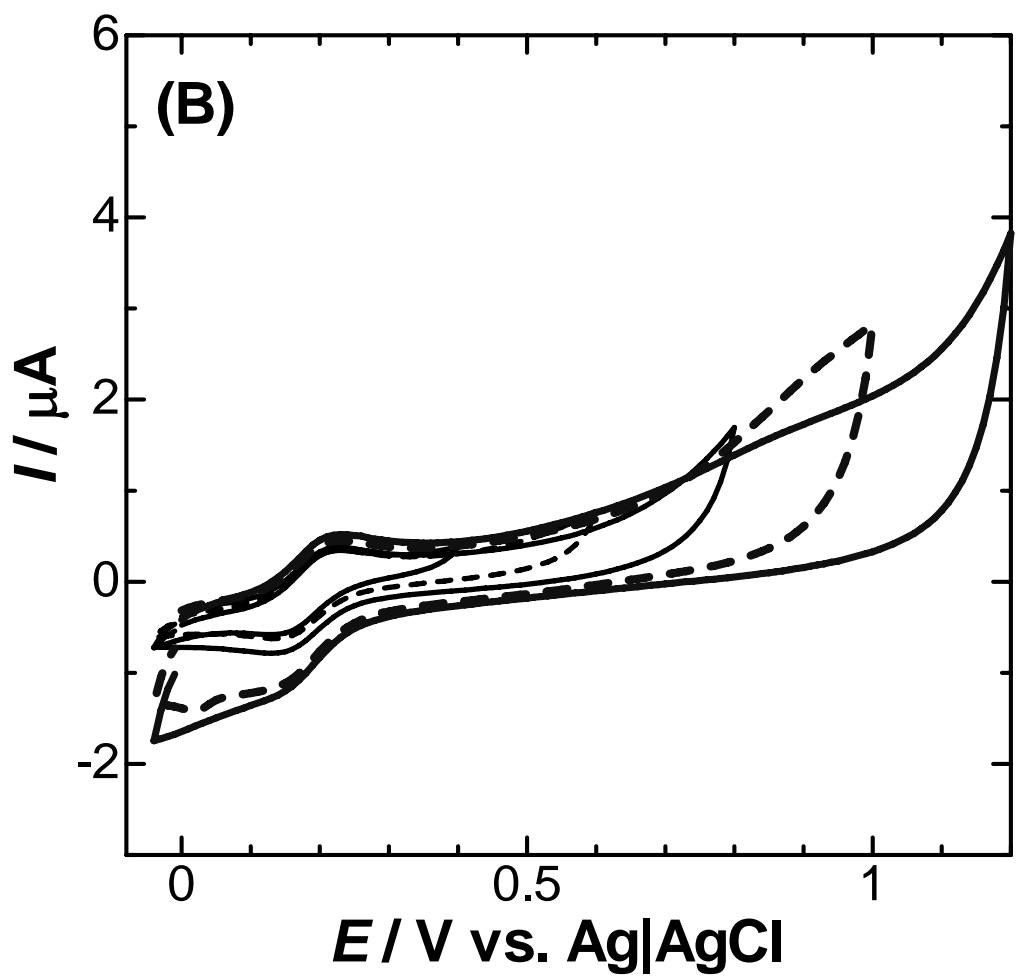

Fig. 5B 


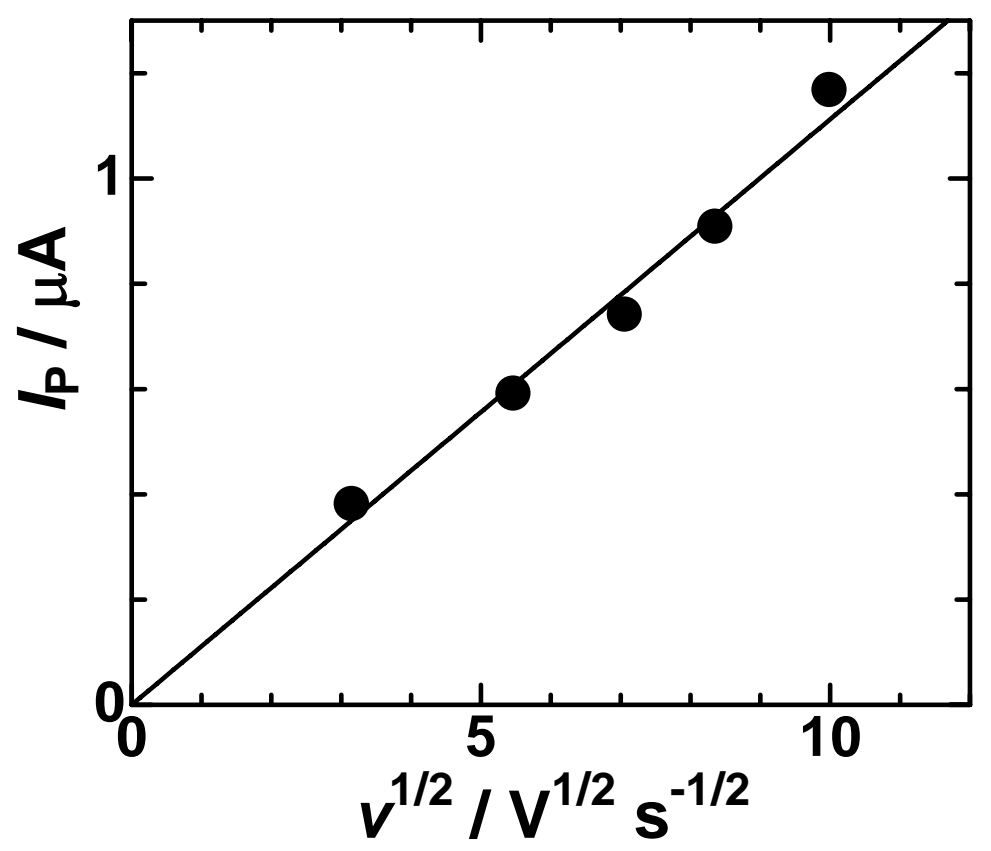

Fig. 6

\section{References}

[1] H. B. Beer, Br. Patent 1147 (1965) 442.

[2] O. De Nora, A. Nidola, G. Trisoglio, G. Bianchi, Br. Patent 1399 (1976) 576.

[3] P. C. S. Hayfield, Plat. Met. Rev. 42 (1998) 27.

[4] S. Trasatti, Electrochim. Acta 45 (2000) 2377.

[5] Y. S. Huang, H. L. Park, F. H. Pollak, Mater. Res. Bull. 17 (1983) 1305.

[6] L. I. Krishtalik, Electrochim. Acta 26 (1981) 329.

[7] A. C. C. Tseung, S. Jasem, Electrochim. Acta 22 (1977) 31.

[8] T. Arikado, C. Iwakura and H. Tamura, Electrochim. Acta 23 (1978) 9.

[9] M. Lim, K. Chiang, R. Amal, J. Photochem. Photobio. A, 183 (2006) 126.

[10] L. Thompson, J. Dubow, K. Rajeshwar, J. Electrochem. Soc. 129 (1982) 1934. 
[11] W. J. Vining, T. J. Meyer, J. Electroanal. Chem. 195 (1985) 183.

[12] J. Kiwi, M. Gratzel, Chem. Phys. Let. 78 (1981) 241.

[13] C. D. Ellis, J. A. Gilbert, W. R. Murphy Jr., T. J. Meyer, J. Am. Chem. Soc.105 (1983) 4842.

[14] A. Mills, D. Worsley, J. Chem. Soc., Faraday Trans., 87 (1991) 3275.

[15] S. Ferrere, B. A. Gregg, J. Chem. Soc., Faraday Trans., 94 (1998) 2827.

[16] B. C. Gilbert, J. K. Stell, W. J. Peet, K. J. Radford, J. Chem. Soc., Faraday Trans. 1, 84 (1988) 3319.

[17] C. K. Njue, J. F. Rusling, J. Am. Chem. Soc. 122 (2000) 6459.

[18] X. Zu, J. F. Rusling, Langmuir 13 (1997) 3693.

[19] T. Takei, H. Sakai, Y. Kondo, N. Yoshino, M. Abe, Colloid. Surf. A 183-185 (2001) 757.

[20] Y. Ohsawa, S. Aoyagui, J. Electroanal. Chem. 145 (1983) 109.

[21] J. Chen, S. Ikeda, K. Aoki, J. Electroanal. Chem. 496 (2001) 88.

[22] R. E. Bozak, Photochemistry in the metallocenes, ed. J. N. Pitts, Jr., G. S.

Hammond, W. A. Noyes, Jr., in Advances in Photochemistry 8, p. 227-244, 1971,

New York.

[23] J. C. Zahner, H. G. Drickamer, J. Chem. Phys. 35 (1961) 375.

[24] K. Aoki, P. Tasakorn, J. Chen, J. Electroanal. Chem. 542 (2003) 51.

[25] J. Chen, M. Sato, J. Electroanal. Chem. 572 (2004) 153.

[26] Z. Yang, J. Zhao, Y. Lu, Z. Du, Z.Yang, Chem. Phys. 307 (2004) 71.

[27] I. D. Charlton, A. P. Doherty, Anal. Chem. 72 (2000) 687.

[28] K. Aoki, K. Tokuda and H. Matsuda, J. Electroanal. Chem., 199 (1986) 69. 